\title{
A BIODIVERSIDADE DA FAUNA E DA FLORA DA CAATINGA NO CANCIONEIRO REGIONAL
}

\author{
Júlio Henrique Nascimento da Silva ${ }^{1}$ \\ Claudemiro de Lima Junior ${ }^{2}$ \\ Elâine Maria dos Santos Ribeiro ${ }^{3}$ \\ Regina Lúcia Félix de Aguiar Lima ${ }^{4}$
}

Resumo: O método tradicional de ensino onde os alunos têm participação passiva no processo de aprendizagem ainda é comum nas escolas, e para mudar esse cenário as metodologias ativas de ensino têm sido adotadas no processo educativo. Recursos didáticos como jogos lúdicos podem ser ferramentas para melhorar o processo de ensino-aprendizagem. O objetivo deste trabalho foi desenvolver um jogo musical como ferramenta didática para o ensino da diversidade da fauna e da flora da Caatinga. O jogo aborda o tema de forma divertida estimulando os alunos o interesse sobre o tema promovendo um conhecimento mais aprofundado sobre a fauna e a flora, buscando despertar nos alunos a conscientização sobre a importância da conservação da Caatinga.

Palavras-chave: Semiárido Brasileiro; Música; Jogo Educacional; Diversidade Biológica; Metodologia Ativa.

Abstract: The traditional teaching method where students have a passive participation in the learning process is still common in schools, and to change this scenario, active teaching methodologies have been adopted in the educational process. Teaching resources such as playful games can be tools to improve the teaching-learning process. The objective of this work was to develop a musical game as a didactic tool for teaching about the diversity of the fauna and flora of the Caatinga. The game approaches the theme in a fun way, stimulating students 'interest in the theme, promoting knowledge about the fauna and flora, and seeking to raise students' awareness about the importance of Caatinga conservation.

Keywords: Brazilian Semi-arid; Music; Educational Game; Biological Diversity; Active Methodology.

${ }^{1}$ Universidade de Pernambuco, E-mail: julio.henriquenascimento@upe.br. http://lattes.cnpq.br/3654436466830671

2 Universidade de Pernambuco, E-mail: claudemiro.lima@upe.br. http://lattes.cnpq.br/8114711170508132

3 Universidade de Pernambuco, E-mail: elaine.ribeiro@upe.br. http://lattes.cnpq.br/3304685448889789

4 Universidade de Pernambuco, E-mail: regina.aguiar@upe.br. http://lattes.cnpq.br/8549101690272163 


\section{Introdução}

O processo de ensino tradicional ainda predomina nas escolas de um modo geral, o qual é baseado na transmissão de conteúdos pelo professor, num modelo denominado por Freire (2016) de Educação Bancária. Esse sistema não favorece o processo de ensino-aprendizagem, pois é um método que parte do pressuposto de que o professor é o detentor de todo o saber. No modelo de ensino tradicional o professor atua predominantemente na exposição dos conteúdos da forma como estão apresentados no livro didático e de forma monológica, tendo assim, baixa eficiência e pouca interação entre professor e aluno (CRUZ; OLIVEIRA, 2007; VIEIRA, 2014).

A aplicação de metodologias ativas de ensino coloca os alunos numa situação em que devem ter participação ativa na busca do conhecimento, permitindo maior interação entre alunos e professores durante as aulas, tornando o processo de ensino-aprendizagem mais eficaz e promovendo aprendizagem significativa (PEIXOTO, 2016). Existem diversas ferramentas ou estratégias que podem ser utilizadas durante o processo de ensino para melhorar a eficiência da aprendizagem como, por exemplo, as aulas práticas e demonstrativas, a utilização de jogos didáticos variados, realização de projetos, promoção de debates e dinâmicas diversas. Até mesmo a própria aula expositiva pode receber incrementos e ter momentos com atividades mais interativas, contudo, o professor precisa ter perspicácia de ser capaz de atender a todas as especificidades do processo de aprendizagem, estar motivado e ter disponibilidade de tempo para se dedicar a realizar aulas e atividades, utilizando as metodologias ativas (KRASILCHIK, 2004; CAMARGO; DAROS, 2018).

O estudo da Caatinga e da sua biodiversidade faz parte dos conteúdos abordados na educação básica, sendo um tema especialmente importante nas escolas situadas na área de abrangência desse ecossistema. A Caatinga é uma região fitogeográfica localizada na região do semiárido nordestino e, apesar de sua vegetação típica ser descrita como Florestas e Arbustais Tropicais Sazonalmente Secas, a Caatinga possui uma grande diversidade de espécies, chegando a algo em torno de 1.400 animais vertebrados, em que aproximadamente $23 \%$ são endêmicos (GARDA et al. 2018; FERNANDES; QUEIROZ, 2018). Isso representa uma alta diversidade biológica, sendo uma das florestas secas mais biodiversas do mundo; contudo, ainda é bastante ameaçada por diversos fatores antrópicos, como a caça, desmatamento, queimadas e urbanização (LEAL et al. 2003).

Nesse contexto, a utilização de estratégias baseadas em metodologias ativas e Educação Ambiental no ambiente escolar podem promover a reflexão sobre esses problemas ambientais e sensibilizar os alunos na compreensão da

importância do conhecimento da biodiversidade da Caatinga e sua conservação. O objetivo deste trabalho foi desenvolver um jogo musical que possa ser utilizado como ferramenta didática para estimular o aprendizado sobre a fauna e a flora da Caatinga, bem como para promover sua valorização e conservação.

revista brasileira educação ambiental 


\section{A música como recurso didático para a abordagem da fauna e flora da Caatinga no ambiente escolar}

As metodologias de ensino tradicionais (transmissão-recepção) são tidas como ineficientes para o processo de ensino-aprendizagem, e isso tem levantado a necessidade de professores e escolas se reinventarem, buscando novas formas didáticas para trabalhar os conteúdos, incentivando os alunos a pesquisarem e buscarem o conhecimento sobre determinado assunto (CONCEIÇÃO; MOTA; BARGUIL, 2020). A sala de aula deve ser um momento no qual o aluno irá trabalhar as suas dúvidas e questionamentos sobre o que ele pesquisou sobre o assunto, cabendo ao professor a tarefa de mediar a discussão em sala de aula e auxiliar o processo de aprendizagem, trabalhando com recursos didáticos para fechar possíveis lacunas que ficarem, tirando dúvidas e realizando atividades para fixação (FREIRE, 2011). Contudo, a educação praticada nas escolas ainda é muito voltada para a transmissão monóloga de conceitos apresentados em livros didáticos, que, muitas vezes, transmite uma visão pobre dos conteúdos (KIOURANIS; SILVEIRA; SILVA, 2005; VIEIRA, 2014).

Os jogos didáticos são uma ferramenta de ensino de grande importância para o processo de ensino-aprendizagem quando empregados com um propósito definido e não apenas como um recurso para a diversão, mas sim, de mobilização de fatores cognitivos, promovendo a aprendizagem de um conhecimento novo de uma forma interativa e lúdica, contribuindo para o progresso social dos alunos a partir de uma participação ativa, trabalhando em grupo, o que é extremamente importante para a formação de cidadãos (CONCEIÇÂO; MOTA; BARGUIL, 2020; MESSEDER NETO, 2019; SPIEL; SCHWARTZMAN, 2018). Os jogos musicais, por exemplo, podem ser um recurso importante para o professor usar como ferramenta didática, não apenas no ensino de música em si, mas também na construção de outros tipos de conhecimentos, fazendo com que esse seja um recurso valioso e de abordagem interdisciplinar no campo pedagógico (MIRANDA, 2013; ROSÁRIO 2019).

O uso da música brasileira para o ensino da Biologia foi tema do estudo de Ribas e Guimarães (2004), que utilizaram do pop rock brasileiro para trabalhar temas como a reflexão sobre problemas ambientais e fazendo analogias entre diferentes animais. A criação de paródias de músicas que fizeram sucesso no cenário nacional para trabalhar diversas áreas da Biologia como Botânica, Ecologia, Fisiologia e a própria Zoologia, mostrando que metodologias lúdicas podem colaborar para que os alunos tenham um aprendizado mais significativo e eficaz se comparado a metodologias clássicas de ensino (ALMEIDA et al. 2017; LIMA et al. 2018). A utilização da música como recurso didático traz, entre outras vantagens, o baixo custo para que seja implementado, possibilitando que os alunos tenham um momento de interdisciplinaridade, transpondo a barreira da educação tradicional, chegando a ser uma educação cultural também a partir do uso de músicas regionais e populares que representam a cultura e diversidade do país (BARROS; 
ZANELLA; ARAÚJO-JORGE, 2013). Assim, as músicas podem ser utilizadas como ferramenta para promover o aprendizado de conteúdos variados, resultando em aprendizagem significativa e persistente. A proposta do jogo musical irá contribuir para o conhecimento da fauna e da flora da Caatinga, para a valorização desse ecossistema e para a formação de cidadãos comprometidos com a conservação ambiental (ARAÚJO et al. 2020; ROSÁRIO 2019).

A Biologia é uma ciência na qual se estudam a vida e os organismos nos seus diferentes aspectos, analisam-se como estes se relacionam entre si, as funções no ambiente e as características morfológicas e fisiológicas das espécies (CICILLINI, 1993). Ela é considerada uma ciência complexa, que se divide em subáreas como Genética, Microbiologia, Ecologia, Botânica e Zoologia. Segundo os Parâmetros Curriculares Nacionais no estudo de Biologia, deve-se conhecer como os seres humanos e a natureza interagem entre si e as mudanças que o ser humano pode causar à natureza ao manejar os recursos disponíveis nela (BRASIL, 2008). O ensino de Zoologia (fauna) e a Botânica (flora), como parte do estudo da Biologia, precisa promover o entendimento das principais características dos grupos de espécies que incluem, da preferência dos grupos de espécies por habitats e suas relações com outros seres vivos e com o ambiente, além de métodos de manejo e conservação para a sustentabilidade (AZEVEDO et al. 2016).

A Fauna da Caatinga, além de ser altamente diversa, possui um alto nível de endemismo principalmente de répteis e anfíbios (GARDA et al. 2018). Os dados sobre quantidade de espécies de vertebrados da Caatinga subiu bastante de 2003 até 2017 saindo de 1060 para 1439 espécies descritas para todos os grupos de vertebrados, um aumento de quase $36 \%$ na riqueza de espécies conhecidas, comprovando a alta diversidade da região (GARDA et al. 2018; LEAL et al. 2003). Além disso, é esperado ainda conhecer mais espécies deste ambiente, contudo o incentivo para estudos nesse tipo de ambiente ainda é escasso apesar de esse se mostrar um ambiente de grande potencial para novas descobertas principalmente devido a suas características ambientais.

A Flora da Caatinga é constituída principalmente por espécies arbóreas de porte baixo e arbustivas, muitas dessas espécies apresentam características peculiares para lidar com o período de estiagem como folhas pequenas, presença de acúleos e espinhos, deciduidade, xilopódios para armazenamento de água e caule verde para realização de fotossíntese (SENA 2011; FERNANDES; QUEIROZ, 2018). A Caatinga possui diferentes fisionomias, que se referem aos diferentes aspectos visuais da vegetação, que podem variar dependendo das chuvas e dos solos (LEAL et al. 2008). A Caatinga é uma das florestas secas com maior riqueza de espécies de plantas, nela ocorrem mais de 3.000 espécies de angiospermas pertencentes a 152 famílias botânicas, onde as mais representativas são Leguminosae, Euphorbiaceae (QUEIROZ et al. 2017). As famílias que contêm espécies suculentas, Cactaceae e Bromeliaceae, são bem características da Caatinga e 
possuem metabolismo ácido das crassuláceas como estratégia para lidar com a aridez (FERNANDES; QUEIROZ, 2018).

Para auxiliar a valorização e conservação da biodiversidade da fauna e da flora que existe na Caatinga, o uso de recursos didáticos na escola que motivem os alunos e levem os mesmos a refletirem sobre sua importância é uma das ferramentas. Nesse sentido, surgiu a ideia de abordar o conhecimento da diversidade da fauna e da flora da Caatinga num jogo musical destinado à educação básica.

\section{Metodologia}

Foi idealizado um jogo musical no qual seriam usadas músicas, regionais que contenham na letra citação de nomes de espécies de animais e de plantas que ocorrem na Caatinga para ser realizado em sala de aula, no contexto da abordagem do conteúdo sobre biodiversidade da fauna e flora da Caatinga.

A dinâmica desse jogo musical envolve as seguintes etapas prévias: (1) aula inicial sobre a biodiversidade da Caatinga em termos de fauna e flora; (2) apresentação da proposta do jogo pelo professor; (3) preparação individual dos alunos para a realização da atividade; e (4) preparação de fichas pelo professor, as quais devem conter os nomes de espécies da Caatinga que ocorrem na Caatinga e das músicas e colocando em envelopes para sorteio pelos grupos no dia da realização da atividade. $O$ jogo pode ser feito em dois momentos diferentes: um para flora outro para fauna.

$\mathrm{Na}$ aula sobre a diversidade da Caatinga, ministrada pelo professor, devem ser apresentadas espécies de animais e plantas da Caatinga e suas principais características como distribuição, alimentação, caracteres morfológicos, reprodução e tipos de interações ecológicas entre espécies da Caatinga, ou com o ambiente. Ao final da aula, o professor deve apresentar a proposta de realizar o jogo e instruir os alunos para que pesquisem espécies da fauna e da flora da Caatinga presentes em músicas do cancioneiro.

O jogo consiste no fornecimento do nome de uma espécie da Caatinga e, após terem um tempo para pensar, os participantes dos grupos precisam cantar parte de uma música que contenha o nome da espécie. Quem acerta faz ponto no jogo e permanece, sendo vencedor o grupo que tiver mais acertos. Esse jogo foi inspirado em jogos e brincadeiras realizadas comumente pelas crianças e que também aparecem em programas de TV. Para a realização do jogo, o professor deve organizar a turma em grupos, combinar o tempo que as equipes terão para cantar a música contendo o nome da espécie de animal ou planta, e a ordem na qual as equipes vão responder. Cada grupo, por sua vez, escolherá um dos envelopes, que deverão estar empilhados e entregar ao professor. O professor vai ler o nome da espécie sorteada e o grupo, após o tempo estabelecido para pensar, terá a oportunidade de cantar o trecho de uma música que contenha o nome da espécie sorteada. Só marca ponto se 
souber cantar exatamente o trecho que contém o nome da espécie. Caso o grupo que sorteou a ficha não saiba nenhuma música que contenha o nome do animal ou planta, os outros grupos terão a oportunidade de responder, sempre seguindo a ordem de participação no jogo e sem tempo adicional para pensar.

A decisão da quantidade de pessoas no grupo pode ser tomada pelos alunos e pelo professor, bem como o período de tempo que o grupo terá para pensar e dar a resposta musical. Isso deve ser feito levando em conta fatores como a quantidade de alunos na turma e a faixa etária dos alunos. Esse jogo pode ser aplicado tanto em turmas do Ensino Fundamental quanto do Médio.

Propõe-se que a pontuação seja marcada da seguinte maneira: o grupo que acertar uma música na qual o animal tenha sido citado ganha 3 pontos. Caso outros grupos saibam cantar outras músicas diferentes, nas quais o nome da espécie esteja na letra, também podem ganhar os 3 pontos.

Foi criado um banco de dados para esse trabalho, na forma de tabelas, com músicas contendo na letra o nome de espécies de animais e plantas da Caatinga para servir de suporte para o professor na aplicação do jogo. Para isso, foram selecionadas músicas para uso no jogo, a partir do conhecimento musical dos autores e a partir de buscas por músicas de cantores e compositores regionais que retratam a Caatinga ou a diversidade biológica da fauna e da flora do Brasil.

As espécies de animais e de plantas incluídas nas tabelas (Tabelas 1, 2 e 3) foram aquelas citadas nas músicas e que são nativas da Caatinga. Para isto, foi verificada a distribuição das espécies em bancos de dados como o Avibase, eBird, Flora do Brasil e em Moro et al., (2014) para confirmar que as espécies selecionadas realmente ocorram na região. Quando o nome popular citado na música possuía mais de uma espécie, do mesmo gênero, a que poderia se referir adotamos apenas o gênero da espécie e abreviatura sp., pois o uso de nomes populares nas músicas impossibilita uma identificação correta nesses casos.

O jogo pode ser realizado com o uso do banco de dados fornecido neste artigo ou com nomes de espécies de animais e plantas contidos em músicas selecionadas em levantamentos adicionais ser feitos pelos professores e alunos.

O desenvolvimento deste jogo musical faz parte do projeto intitulado "Aprendendo sobre o valor da biodiversidade da Caatinga e seus serviços ecossistêmicos no ensino escolar" apoiado pela Fundação de Amparo a Ciência e Tecnologia do Estado de Pernambuco (APQ - 0177-2.05/18). A construção desse jogo como um recurso didático lúdico foi pensado para que sirva como uma ferramenta para valorização e aprendizagem da Caatinga no ensino básico; contudo, não foi possível testar a sua efetividade em sala de aula devido à pandemia causada pela COVID-19. 


\section{Resultados e Discussão}

O levantamento realizado sobre a fauna e a flora da Caatinga citada em músicas regionais foi organizado em três listas contendo o nome das espécies citadas nas músicas, o nome científico da espécie, o nome da música, dos cantores e compositores.

Em relação à fauna da Caatinga foram encontradas 26 músicas que contém na letra menção a espécies de animais que ocorrem nesse ecossistema, e incluídas em um banco de dados para preparação das tabelas 1 e 2. Nas músicas há citação de duas (2) espécies de animais invertebrados e de 60 espécies de animais vertebrados, que são pertencentes a cinco grupos: peixes (2 espécie), anfíbios (2 espécies) répteis (4 espécies), aves (48 espécies) e mamíferos (6 espécies). Como houve predomínio de espécies de aves, foi construída a Tabela 1 somente com os dados de aves e os demais animais foram agrupados na Tabela 2.

Tabela 1: Fauna da Caatinga: aves que ocorrem na Caatinga presentes na letra de músicas regionais, seus cantores e compositores.

\begin{tabular}{|c|c|c|c|c|}
\hline Nome popular & $\begin{array}{c}\text { Nome científico } \\
\text { (autor) }\end{array}$ & $\begin{array}{l}\text { Nome da } \\
\text { música }\end{array}$ & Cantores & Compositores \\
\hline Acauã & $\begin{array}{l}\text { Herpetotheres } \\
\text { cachinnans } \\
\text { (Linnaeus, 1758) }\end{array}$ & Acauã & Luiz Gonzaga & Zé Dantas \\
\hline \multirow[t]{4}{*}{ Andorinha } & \multirow[t]{4}{*}{ Nyctidromus sp. } & Caatinga & Paulo Soares & $\begin{array}{l}\text { Duduca Moura } \\
\text { Julio C., Pedro C } \\
\text { Paulo Soares }\end{array}$ \\
\hline & & Passaredo & Chico Buarque & $\begin{array}{l}\text { Chico Buarque } \\
\text { Francis Hime }\end{array}$ \\
\hline & & $\begin{array}{l}\text { Panorama } \\
\text { Ecológico }\end{array}$ & Erasmo Carlos & $\begin{array}{l}\text { Erasmo Carlos } \\
\text { Roberto Carlos }\end{array}$ \\
\hline & & $\begin{array}{l}\text { Qué Qui Tu } \\
\text { Tem Canário? }\end{array}$ & Xangai & Xangai \\
\hline Anum & $\begin{array}{l}\text { Crotophaga ani } \\
\text { (Linnaeus, 1758) }\end{array}$ & Passaredo & Chico Buarque & $\begin{array}{l}\text { Chico Buarque } \\
\text { Francis Hime }\end{array}$ \\
\hline Aracuão & $\begin{array}{l}\text { Ortalis araucuan } \\
\text { (Spix, 1825) }\end{array}$ & Cantoria do galo & Xangai & Cantoria do galo \\
\hline \multirow[t]{3}{*}{ Asa branca } & \multirow[t]{3}{*}{$\begin{array}{l}\text { Patagioenas } \\
\text { picazuro } \\
\text { (Temminck, 1813) }\end{array}$} & Asa branca & Luiz Gonzaga & $\begin{array}{l}\text { Humberto } \\
\text { Teixeira } \\
\text { Luiz Gonzaga }\end{array}$ \\
\hline & & Passaredo & Chico Buarque & $\begin{array}{l}\text { Chico Buarque } \\
\text { Francis Hime }\end{array}$ \\
\hline & & $\begin{array}{l}\text { A volta da Asa } \\
\text { branca }\end{array}$ & Luiz Gonzaga & $\begin{array}{l}\text { Humberto } \\
\text { Teixeira } \\
\text { Luiz Gonzaga }\end{array}$ \\
\hline
\end{tabular}

Revbea, São Paulo, V. 15, № 6: 154-172, 2020. 
Tabela 1: Fauna da Caatinga: aves que ocorrem na Caatinga presentes na letra de músicas regionais, seus cantores e compositores (continuação).

\begin{tabular}{|c|c|c|c|c|}
\hline Nome popular & $\begin{array}{l}\text { Nome científico } \\
\text { (autor) }\end{array}$ & $\begin{array}{l}\text { Nome da } \\
\text { música }\end{array}$ & Cantores & Compositores \\
\hline Assum preto & $\begin{array}{l}\text { Gnorimopsar } \\
\text { chopi } \\
\text { (Leverkühn, 1889) }\end{array}$ & Assum preto & Luiz Gonzaga & $\begin{array}{l}\text { Humberto } \\
\text { Teixeira } \\
\text { Luiz Gonzaga }\end{array}$ \\
\hline \multirow[t]{2}{*}{ Bem-te-vi } & $\begin{array}{l}\text { Pitangus } \\
\text { sulphuratus } \\
\text { (Linnaeus, 1766) }\end{array}$ & Passaredo & Chico Buarque & $\begin{array}{l}\text { Chico Buarque } \\
\text { Francis Hime }\end{array}$ \\
\hline & & $\begin{array}{l}\text { Esquindo de } \\
\text { zombaria }\end{array}$ & Xangai & Capinam, Xangai \\
\hline $\begin{array}{l}\text { Casaca de } \\
\text { couro }\end{array}$ & $\begin{array}{l}\text { Pseudoseisura } \\
\text { cristata } \\
\text { (Spix, 1824) }\end{array}$ & $\begin{array}{l}\text { Casaca de } \\
\text { couro }\end{array}$ & $\begin{array}{l}\text { Jackson do } \\
\text { Pandeiro }\end{array}$ & $\begin{array}{l}\text { Rui De Morais } \\
\text { Silva }\end{array}$ \\
\hline \multirow[t]{2}{*}{$\begin{array}{l}\text { Canário-da- } \\
\text { terra }\end{array}$} & $\begin{array}{l}\text { Sicalis flaveola } \\
\text { (Linnaeus, 1766) }\end{array}$ & $\begin{array}{l}\text { Qué Qui Tu } \\
\text { Tem Canário? }\end{array}$ & Xangai & Xangai \\
\hline & & $\begin{array}{l}\text { Panorama } \\
\text { Ecológico }\end{array}$ & Erasmo Carlos & $\begin{array}{l}\text { Erasmo Carlos } \\
\text { Roberto Carlos }\end{array}$ \\
\hline Carcará & $\begin{array}{l}\text { Caracara plancus } \\
\text { (Miller, 1777) }\end{array}$ & Carcará & João do Vale & $\begin{array}{l}\text { João do Vale } \\
\text { José Cândido }\end{array}$ \\
\hline Carimbamba & $\begin{array}{l}\text { Nyctidromus } \\
\text { albicollis } \\
\text { (Gmelin, 1789) }\end{array}$ & Amanhã eu vou & Luiz Gonzaga & $\begin{array}{l}\text { Luiz Gonzaga } \\
\text { Beduino }\end{array}$ \\
\hline Codorniz & $\begin{array}{l}\text { Nothura maculosa } \\
\text { (Temminck, 1815) }\end{array}$ & Cantoria do galo & Xangai & Xangai \\
\hline Coleiro & $\begin{array}{l}\text { Sporophila } \\
\text { caerulescens } \\
\text { (Vieillot, 1823) }\end{array}$ & Passaredo & Chico Buarque & $\begin{array}{l}\text { Chico Buarque } \\
\text { Francis Hime }\end{array}$ \\
\hline Colibri & $\begin{array}{l}\text { Colibri serrirostris } \\
\text { (Vieillot, 1816) }\end{array}$ & Passaredo & Chico Buarque & $\begin{array}{l}\text { Chico Buarque } \\
\text { Francis Hime }\end{array}$ \\
\hline \multirow[t]{3}{*}{ Curió } & \multirow[t]{3}{*}{$\begin{array}{l}\text { Sporophila angolensis } \\
\text { (Linnaeus, 1766) }\end{array}$} & Caatinga & $\begin{array}{l}\text { Paulo } \\
\text { Soares }\end{array}$ & $\begin{array}{l}\text { Duduca Moura } \\
\text { Julio C., Pedro C. } \\
\text { Paulo Soares }\end{array}$ \\
\hline & & $\begin{array}{l}\text { Qué Qui Tu } \\
\text { Tem Canário? }\end{array}$ & Xangai & Xangai \\
\hline & & $\begin{array}{l}\text { Panorama } \\
\text { Ecológico }\end{array}$ & $\begin{array}{l}\text { Erasmo } \\
\text { Carlos }\end{array}$ & $\begin{array}{l}\text { Erasmo Carlos } \\
\text { Roberto Carlos }\end{array}$ \\
\hline Engole-vento & $\begin{array}{l}\text { Dendrocygna viduata } \\
\text { (Linnaeus, 1766) }\end{array}$ & Passaredo & $\begin{array}{l}\text { Chico } \\
\text { Buarque }\end{array}$ & $\begin{array}{l}\text { Chico Buarque } \\
\text { Francis Hime }\end{array}$ \\
\hline Gavião peneira & $\begin{array}{l}\text { Elanus leucurus } \\
\text { (Vieillot, 1818) }\end{array}$ & $\begin{array}{l}\text { Qué Qui Tu } \\
\text { Tem Canário? }\end{array}$ & Xangai & Xangai \\
\hline Graúna & $\begin{array}{l}\text { Gnorimopsar chopi } \\
\text { (Vieillot, 1819) }\end{array}$ & $\begin{array}{l}\text { Panorama } \\
\text { Ecológico }\end{array}$ & $\begin{array}{l}\text { Erasmo } \\
\text { Carlos }\end{array}$ & $\begin{array}{l}\text { Erasmo Carlos } \\
\text { Roberto Carlos }\end{array}$ \\
\hline Inhambu & $\begin{array}{l}\text { Crypturellus parvirostri } \\
\text { (Wagler, 1827) }\end{array}$ & Passaredo & $\begin{array}{l}\text { Chico } \\
\text { Buarque }\end{array}$ & $\begin{array}{l}\text { Chico Buarque } \\
\text { Francis Hime }\end{array}$ \\
\hline
\end{tabular}


Tabela 1. Fauna da Caatinga: aves que ocorrem na Caatinga presentes na letra de músicas regionais, seus cantores e compositores (continuação).

\begin{tabular}{|c|c|c|c|c|}
\hline Nome popular & $\begin{array}{l}\text { Nome científico } \\
\text { (autor) }\end{array}$ & $\begin{array}{l}\text { Nome da } \\
\text { música }\end{array}$ & Cantores & Compositores \\
\hline Jacurutu & $\begin{array}{l}\text { Bubo virginianus } \\
\text { (Gmelin, 1788) }\end{array}$ & Caatinga & $\begin{array}{l}\text { Paulo } \\
\text { Soares }\end{array}$ & $\begin{array}{l}\text { Duduca Moura } \\
\text { Julio C., Pedro C. } \\
\text { Paulo Soares }\end{array}$ \\
\hline João de barro & $\begin{array}{l}\text { Furnarius rufus } \\
\text { (Gmelin, 1788) }\end{array}$ & João de barro & Sergio Reis & $\begin{array}{l}\text { Muibo Cury } \\
\text { Teddy Vieira }\end{array}$ \\
\hline \multirow[t]{3}{*}{ Juriti } & \multirow[t]{3}{*}{$\begin{array}{l}\text { Leptotila verreauxi } \\
\text { (Bonaparte, 1855) }\end{array}$} & Caatinga & $\begin{array}{l}\text { Paulo } \\
\text { Soares }\end{array}$ & $\begin{array}{l}\text { Duduca Moura } \\
\text { Julio C., Pedro C. } \\
\text { Paulo Soares }\end{array}$ \\
\hline & & Passaredo & $\begin{array}{l}\text { Chico } \\
\text { Buarque }\end{array}$ & $\begin{array}{l}\text { Chico Buarque } \\
\text { Francis Hime }\end{array}$ \\
\hline & & $\begin{array}{l}\text { Esquindo de } \\
\text { zombaria }\end{array}$ & Xangai & $\begin{array}{l}\text { Capinam } \\
\text { Xangai }\end{array}$ \\
\hline $\begin{array}{l}\text { Melro } \\
\text { (graúna) }\end{array}$ & $\begin{array}{l}\text { Gnorimopsar chopi } \\
\text { (Vieillot, 1819) }\end{array}$ & Passaredo & $\begin{array}{l}\text { Chico } \\
\text { Buarque }\end{array}$ & $\begin{array}{l}\text { Chico Buarque } \\
\text { Francis Hime }\end{array}$ \\
\hline \multirow[t]{2}{*}{ Pardal } & \multirow[t]{2}{*}{$\begin{array}{l}\text { Passer domesticus } \\
\text { (Linnaeus, 1758) }\end{array}$} & Passaredo & $\begin{array}{l}\text { Chico } \\
\text { Buarque }\end{array}$ & $\begin{array}{l}\text { Chico Buarque } \\
\text { Francis Hime }\end{array}$ \\
\hline & & $\begin{array}{l}\text { Panorama } \\
\text { Ecológico }\end{array}$ & $\begin{array}{l}\text { Erasmo } \\
\text { Carlos }\end{array}$ & $\begin{array}{l}\text { Erasmo Carlos } \\
\text { Roberto Carlos }\end{array}$ \\
\hline \multirow[t]{2}{*}{ Patativa } & \multirow{2}{*}{$\begin{array}{l}\text { Sporophila plumbea } \\
\text { (Wied, 1830) }\end{array}$} & Patativa & $\begin{array}{l}\text { Vicente } \\
\text { Celestino }\end{array}$ & Vicente Celestino \\
\hline & & Passaredo & $\begin{array}{l}\text { Chico } \\
\text { Buarque }\end{array}$ & $\begin{array}{l}\text { Chico Buarque } \\
\text { Francis Hime }\end{array}$ \\
\hline $\begin{array}{l}\text { Pescador- } \\
\text { Martim }\end{array}$ & $\begin{array}{l}\text { Chloroceryle americana } \\
\text { (Gmelin, 1788) }\end{array}$ & Passaredo & $\begin{array}{l}\text { Chico } \\
\text { Buarque }\end{array}$ & $\begin{array}{l}\text { Chico Buarque } \\
\text { Francis Hime }\end{array}$ \\
\hline Pintassilgo & $\begin{array}{l}\text { Spinus } \\
\text { magellanicus } \\
\text { (Vieillot, 1805) }\end{array}$ & Passaredo & Chico Buarque & $\begin{array}{l}\text { Chico Buarque } \\
\text { Francis Hime }\end{array}$ \\
\hline Pintarroxo & $\begin{array}{l}\text { Todirostrum } \\
\text { cinereum } \\
\text { (Linnaeus, 1766) }\end{array}$ & Passaredo & Chico Buarque & $\begin{array}{l}\text { Chico Buarque } \\
\text { Francis Hime }\end{array}$ \\
\hline Pomba & $\begin{array}{l}\text { Columba livia } \\
\text { (Gmelin, 1789) }\end{array}$ & $\begin{array}{l}\text { Panorama } \\
\text { Ecológico }\end{array}$ & Erasmo Carlos & $\begin{array}{l}\text { Erasmo Carlos } \\
\text { Roberto Carlos }\end{array}$ \\
\hline Quero-Quero & $\begin{array}{l}\text { Vanellus chilensis } \\
\text { (Molina, 1782) }\end{array}$ & Passaredo & Chico Buarque & $\begin{array}{l}\text { Chico Buarque } \\
\text { Francis Hime }\end{array}$ \\
\hline $\begin{array}{l}\text { Ribaçã } \\
\text { (Arribação) }\end{array}$ & $\begin{array}{l}\text { Zenaida auriculata } \\
\text { (Des Murs, 1847) }\end{array}$ & $\begin{array}{l}\text { Paraíba } \\
\text { mulher macho }\end{array}$ & Luiz Gonzaga & Luiz Gonzaga \\
\hline \multirow[t]{2}{*}{ Rolinha } & \multirow[t]{2}{*}{$\begin{array}{l}\text { Columbina talpacoti } \\
\text { (Temminck, 1810) }\end{array}$} & Caatinga & Paulo Soares & $\begin{array}{l}\text { Duduca Moura } \\
\text { Julio C./ Pedro C. } \\
\text { Paulo Soares }\end{array}$ \\
\hline & & Passaredo & Chico Buarque & $\begin{array}{l}\text { Chico Buarque } \\
\text { Francis Hime }\end{array}$ \\
\hline
\end{tabular}


Tabela 1. Fauna da Caatinga: aves que ocorrem na Caatinga presentes na letra de músicas regionais, seus cantores e compositores (continuação).

\begin{tabular}{|c|c|c|c|c|}
\hline Nome popular & $\begin{array}{l}\text { Nome científico } \\
\text { (autor) }\end{array}$ & $\begin{array}{l}\text { Nome da } \\
\text { música }\end{array}$ & Cantores & Compositores \\
\hline \multirow[t]{3}{*}{ Rouxinol } & \multirow{3}{*}{$\begin{array}{l}\text { Troglodytes } \\
\text { musculus } \\
\text { (Naumann, 1823) }\end{array}$} & O Rouxinol & Gilberto Gil & $\begin{array}{l}\text { Gilberto Gil } \\
\text { Jorge Mautner }\end{array}$ \\
\hline & & Pés de milho & Xangai & Jatobá \\
\hline & & Passaredo & Chico Buarque & $\begin{array}{l}\text { Chico Buarque } \\
\text { Francis Hime }\end{array}$ \\
\hline \multirow[t]{4}{*}{ Sabiá } & \multirow[t]{4}{*}{ Turdus sp. } & $\begin{array}{l}\text { Qué Qui Tu } \\
\text { Tem Canário? }\end{array}$ & Xangai & Xangai \\
\hline & & $\begin{array}{l}\text { Majestade } \\
\text { o Sabiá }\end{array}$ & $\begin{array}{l}\text { Roberta } \\
\text { Miranda }\end{array}$ & Roberta Miranda \\
\hline & & Sabiá & Luiz Gonzaga & $\begin{array}{l}\text { Luiz Gonzaga } \\
\text { Zé Dantas }\end{array}$ \\
\hline & & Meninos & Xangai & Juraildes da Cruz \\
\hline \multirow[t]{2}{*}{ Sanhaço } & \multirow[t]{2}{*}{$\begin{array}{l}\text { Tangara sayaca } \\
\text { (Linnaeus, 1766) }\end{array}$} & $\begin{array}{l}\text { Panorama } \\
\text { Ecológico }\end{array}$ & Erasmo Carlos & $\begin{array}{l}\text { Erasmo Carlos } \\
\text { Roberto Carlos }\end{array}$ \\
\hline & & Passaredo & Chico Buarque & $\begin{array}{l}\text { Chico Buarque } \\
\text { Francis Hime }\end{array}$ \\
\hline \multirow[t]{3}{*}{$\begin{array}{l}\text { Sariema/ } \\
\text { Seriema/ } \\
\text { Siriema }\end{array}$} & \multirow[t]{3}{*}{$\begin{array}{l}\text { Cariama cristata } \\
\text { (Linnaeus, 1766) }\end{array}$} & Caatinga & Paulo Soares & $\begin{array}{l}\text { Duduca Moura } \\
\text { Julio C./ Pedro C } \\
\text { Paulo Soares }\end{array}$ \\
\hline & & $\begin{array}{l}\text { ABC do } \\
\text { preguiçoso }\end{array}$ & Xangai & Xangai \\
\hline & & $\begin{array}{l}\text { Cantoria do } \\
\text { galo }\end{array}$ & Xangai & Xangai \\
\hline Sem-fim & $\begin{array}{l}\text { Tapera naevia } \\
\text { (Linnaeus, 1766) }\end{array}$ & Passaredo & $\begin{array}{l}\text { Chico } \\
\text { Buarque }\end{array}$ & $\begin{array}{l}\text { Chico Buarque } \\
\text { Francis Hime }\end{array}$ \\
\hline Sofrê & $\begin{array}{l}\text { Icterus jamacaii } \\
\text { (Gmelin, 1788) }\end{array}$ & Sofrê & $\begin{array}{l}\text { Roberto } \\
\text { Malvezzi }\end{array}$ & Roberto Malvezzi \\
\hline Sururina & $\begin{array}{l}\text { Crypturellus soui } \\
\text { (Hermann, 1783) }\end{array}$ & Luar do sertão & $\begin{array}{l}\text { Luiz } \\
\text { Gonzaga }\end{array}$ & $\begin{array}{l}\text { Catulo da Paixão } \\
\text { Cearense } \\
\text { João Pernambuco }\end{array}$ \\
\hline Tico-Tico & $\begin{array}{l}\text { Zonotrichia capensis } \\
\text { (Statius Muller, 1776) }\end{array}$ & Passaredo & $\begin{array}{l}\text { Chico } \\
\text { Buarque }\end{array}$ & $\begin{array}{l}\text { Chico Buarque } \\
\text { Francis Hime }\end{array}$ \\
\hline Tiê-sangue & $\begin{array}{l}\text { Ramphocelus bresilius } \\
\text { (Linnaeus, 1766) }\end{array}$ & Passaredo & $\begin{array}{l}\text { Chico } \\
\text { Buarque }\end{array}$ & $\begin{array}{l}\text { Chico Buarque } \\
\text { Francis Hime }\end{array}$ \\
\hline Tuju & $\begin{array}{l}\text { Lurocalis semitorquatus } \\
\text { (Gmelin, 1789) }\end{array}$ & Passaredo & $\begin{array}{l}\text { Chico } \\
\text { Buarque }\end{array}$ & $\begin{array}{l}\text { Chico Buarque } \\
\text { Francis Hime }\end{array}$ \\
\hline Tuim & $\begin{array}{l}\text { Forpus xanthopterygius } \\
\text { (Spix, 1824) }\end{array}$ & Passaredo & $\begin{array}{l}\text { Chico } \\
\text { Buarque }\end{array}$ & $\begin{array}{l}\text { Chico Buarque } \\
\text { Francis Hime }\end{array}$ \\
\hline
\end{tabular}


Tabela 1. Fauna da Caatinga: aves que ocorrem na Caatinga presentes na letra de músicas regionais, seus cantores e compositores (continuação).

\begin{tabular}{lllll}
\hline \multicolumn{1}{c}{$\begin{array}{c}\text { Nome } \\
\text { popular }\end{array}$} & \multicolumn{1}{c}{$\begin{array}{c}\text { Nome científico } \\
\text { (autor) }\end{array}$} & Nome da música & Cantores & Compositores \\
\hline Utiariti & $\begin{array}{l}\text { Falco sparverius } \\
\text { (Linnaeus, 1758) }\end{array}$ & Passaredo & $\begin{array}{l}\text { Chico } \\
\text { Buarque }\end{array}$ & $\begin{array}{l}\text { Chico Buarque } \\
\text { Francis Hime }\end{array}$ \\
\hline Urubu & $\begin{array}{l}\text { Coragyps atratus } \\
\text { (Bechstein, 1793) }\end{array}$ & $\begin{array}{l}\text { ABC do } \\
\text { preguiçoso }\end{array}$ & Xangai & Xangai \\
\hline $\begin{array}{l}\text { Vin vin } \\
\text { Vem vem }\end{array}$ & $\begin{array}{l}\text { Euphonia chlorotica } \\
\text { (Linnaeus, 1766) }\end{array}$ & Roendo unha & $\begin{array}{l}\text { Luiz } \\
\text { Gonzaga }\end{array}$ & $\begin{array}{l}\text { Luiz Gonzaga } \\
\text { Luiz Ramalho }\end{array}$ \\
\cline { 2 - 5 } & Quín nem vem vem & $\begin{array}{l}\text { Maciel } \\
\text { Melo }\end{array}$ & Maciel Melo \\
\hline Viúva & $\begin{array}{l}\text { Colonia colonus } \\
\text { (Vieillot, 1818) }\end{array}$ & Passaredo & $\begin{array}{l}\text { Chico } \\
\text { Buarque }\end{array}$ & $\begin{array}{l}\text { Chico Buarque } \\
\text { Francis Hime }\end{array}$ \\
\hline $\begin{array}{l}\text { Zabelê } \\
\text { (VU) }\end{array}$ & $\begin{array}{l}\text { Crypturellus noctivagus } \\
\text { (Wied, 1820) }\end{array}$ & $\begin{array}{l}\text { Qué Qui Tu Tem } \\
\text { Canário? }\end{array}$ & Xangai & Xangai \\
\hline
\end{tabular}

Fonte: Autoria própria.

Grau de risco de extinção: VU - Vulnerável; EN - Em perigo segundo a Lista Nacional Oficial de Espécies da Fauna Ameaçadas de Extinção (BRASIL, 2014).

Tabela 2. Fauna da Caatinga: artrópodes, peixes, anfíbios reptéis, e mamíferos que ocorrem na Caatinga citados na letra de músicas regionais, seus cantores e compositores.

\begin{tabular}{|c|c|c|c|c|}
\hline $\begin{array}{c}\text { Grupo/ } \\
\text { Nome } \\
\text { popular }\end{array}$ & $\begin{array}{l}\text { Nome científico } \\
\text { (autor) }\end{array}$ & $\begin{array}{l}\text { Nome da } \\
\text { música }\end{array}$ & Cantores & Compositores \\
\hline \multicolumn{5}{|l|}{ Artrópodes } \\
\hline Carrapato & Ixodida sp. & Meninos & Xangai & Juraildes da Cruz \\
\hline Tanajura & Atta sp. & Meninos & Xangai & Juraildes da Cruz \\
\hline \multicolumn{5}{|l|}{ Peixes } \\
\hline Piranha & Serrasalminae sp. & $\begin{array}{l}\text { Panorama } \\
\text { Ecológico }\end{array}$ & Erasmo Carlos & $\begin{array}{l}\text { Erasmo Carlos } \\
\text { Roberto Carlos }\end{array}$ \\
\hline Surubim & $\begin{array}{l}\text { Pseudoplatystoma } \\
\text { corruscans } \\
\text { (Spix \& Agassiz, 1829) }\end{array}$ & $\begin{array}{l}\text { Boato } \\
\text { Ribeirinho }\end{array}$ & $\begin{array}{l}\text { Targino } \\
\text { Gondim } \\
\text { Elba Ramalho }\end{array}$ & $\begin{array}{l}\text { Nilton Freitas } \\
\text { Wilson Freitas } \\
\text { Wilson Duarte }\end{array}$ \\
\hline \multicolumn{5}{|l|}{ Anfíbios } \\
\hline Sapo & Bufo sp. & $\begin{array}{l}\text { Cantiga de } \\
\text { Sapo }\end{array}$ & $\begin{array}{l}\text { Jackson do } \\
\text { Pandeiro }\end{array}$ & $\begin{array}{l}\text { Buco do Pandeiro } \\
\text { Jackson do } \\
\text { Pandeiro }\end{array}$ \\
\hline Caçote & Leptodactylus sp. & $\begin{array}{l}\text { Desafio do } \\
\text { Auto da } \\
\text { Catingueira }\end{array}$ & Elomar & Elomar \\
\hline
\end{tabular}

Revbea, São Paulo, V. 15, № 6: 154-172, 2020. 
Tabela 2. Fauna da Caatinga: artrópodes, peixes, anfíbios reptéis, e mamíferos que ocorrem na Caatinga citados na letra de músicas regionais, seus cantores e compositores

(continuação).

\begin{tabular}{|c|c|c|c|c|}
\hline $\begin{array}{c}\text { Grupo/ } \\
\text { Nome } \\
\text { popular }\end{array}$ & $\begin{array}{l}\text { Nome científico } \\
\text { (autor) }\end{array}$ & $\begin{array}{l}\text { Nome da } \\
\text { música }\end{array}$ & Cantores & Compositores \\
\hline \multicolumn{5}{|l|}{ Répteis } \\
\hline $\begin{array}{l}\text { Calango, } \\
\text { calango de } \\
\text { cauda verde }\end{array}$ & $\begin{array}{l}\text { Ameivula venetacaudus } \\
\text { (Spix, 1825) }\end{array}$ & Caatinga & Paulo Soares & $\begin{array}{l}\text { Duduca Moura } \\
\text { Julio C./ Pedro C. } \\
\text { Paulo Soares }\end{array}$ \\
\hline Cascavel & $\begin{array}{l}\text { Crotalus durissus } \\
\text { (Linnaeus, 1758) }\end{array}$ & $\begin{array}{l}\text { Erva } \\
\text { venenosa }\end{array}$ & Rita Lee & $\begin{array}{l}\text { Mike Stoller } \\
\text { Jerry Leiber } \\
\text { Rossini Pinto }\end{array}$ \\
\hline Jararaca & $\begin{array}{l}\text { Bothrops erythromelas } \\
\text { (Amaral, 1923) }\end{array}$ & Caatinga & Paulo Soares & $\begin{array}{l}\text { Duduca Moura } \\
\text { Julio C./ Pedro C. } \\
\text { Paulo Soares }\end{array}$ \\
\hline Jibóia & $\begin{array}{l}\text { Boa constrictor } \\
\text { (Linnaeus, 1758) }\end{array}$ & Xangai & Xangai & Juraildes Da Cruz \\
\hline \multicolumn{5}{|l|}{ Mamíferos } \\
\hline Mocó & $\begin{array}{l}\text { Kerodon rupestres } \\
\text { (Wied-Neuwied, 1820) }\end{array}$ & $\begin{array}{l}\text { ABC do } \\
\text { preguiçoso }\end{array}$ & Xangai & Xangai \\
\hline $\begin{array}{l}\text { Onça preta } \\
\text { (VU) }\end{array}$ & $\begin{array}{l}\text { Panthera onca } \\
\text { (Linnaeus, 1758) }\end{array}$ & Caatinga & Paulo Soares & $\begin{array}{l}\text { Duduca Moura } \\
\text { Julio C., Pedro C. } \\
\text { Paulo Soares }\end{array}$ \\
\hline $\begin{array}{l}\text { Sussuarana } \\
\text { (VU) }\end{array}$ & $\begin{array}{l}\text { Puma concolor } \\
\text { (Linnaeus, 1771) }\end{array}$ & Capim guiné & Raul Seixas & Raul Seixas \\
\hline Quati & $\begin{array}{l}\text { Nasua nasua } \\
\text { (Linnaeus, 1758) }\end{array}$ & $\begin{array}{l}\text { Desafio do } \\
\text { Auto da } \\
\text { Catingueira }\end{array}$ & Elomar & Elomar \\
\hline $\begin{array}{l}\text { Tatu } \\
(\text { EN) }\end{array}$ & $\begin{array}{l}\text { Tolypeutes tricinctus } \\
\text { (Linnaeus, 1758) }\end{array}$ & Caatinga & Paulo Soares & $\begin{array}{l}\text { Duduca Moura } \\
\text { Julio C./ Pedro C. } \\
\text { Paulo Soares }\end{array}$ \\
\hline Tamanduá & $\begin{array}{l}\text { Tamandua tetradactyla } \\
\text { (Linnaeus, 1758) }\end{array}$ & Caatinga & Paulo Soares & $\begin{array}{l}\text { Duduca Moura } \\
\text { Julio C./ Pedro C. } \\
\text { Paulo Soares }\end{array}$ \\
\hline
\end{tabular}

Fonte: Autoria própria. Grau de risco de extinção: VU - Vulnerável; EN - Em perigo segundo a Lista Nacional Oficial de Espécies da Fauna Ameaçadas de Extinção (BRASIL, 2014).

Em relação à flora, foram encontradas 17 músicas que citam 39 espécies de plantas que ocorrem na Caatinga. A relação das espécies de plantas desse ecossistema citadas nas músicas está apresentada na Tabela 3, juntamente com informações sobre as músicas, como nome, cantores e compositores. Um aspecto que foi percebido na menção das espécies nas músicas foi relacionado aos diferentes nomes comuns pelos quais as espécies são conhecidas, em que uma mesma espécie foi citada com diferentes nomes comuns nas músicas. Assim, a abordagem da nomenclatura científica e popular dos seres vivos pode ser ilustrada pela realização dessa atividade, com promoção de aprendizagem significativa sobre esse tema também.

Os professores podem tomar as listagens apresentadas nas tabelas 1 , 2 e 3 como base para a realização do jogo proposto na metodologia, a qual 
pode servir de auxílio para os professores usarem as espécies como exemplos na aula que irão funcionar para o desenvolvimento do jogo. Os professores podem ampliar o banco de dados a partir de pesquisas adicionais ou do seu conhecimento musical.

Assim, o professor pode optar por utilizar na aula apenas espécies de animais presentes na tabela, mas, podendo também falar sobre outras espécies que não estejam presentes nas músicas, mas que sejam relevantes ao aprendizado dos alunos, contudo, essas outras espécies não entrariam na dinâmica deste jogo. Algumas das espécies de animais estão presentes na letra de mais de uma música. Os alunos poderão citar trechos de outras músicas que não estejam na lista e que deverão ser válidas, e receberem pontuação no jogo, caso estejam corretas.

Tabela 3: Flora da Caatinga: espécies de plantas que ocorrem na Caatinga presentes na letra de músicas regionais, seus cantores e compositores.

\begin{tabular}{|c|c|c|c|c|}
\hline $\begin{array}{c}\text { Nome } \\
\text { popular }\end{array}$ & $\begin{array}{c}\text { Nome científico } \\
\text { (autor) }\end{array}$ & $\begin{array}{l}\text { Nome da } \\
\text { música }\end{array}$ & Cantores & Compositores \\
\hline Alecrim & Lippia sp. & $\begin{array}{l}\text { Pra fazer } \\
\text { chá }\end{array}$ & Matingueiros & Wagner Miranda \\
\hline Alfazema & $\begin{array}{l}\text { Hyptis suaveolens } \\
\text { (L. Poit.) }\end{array}$ & $\begin{array}{l}\text { Pra fazer } \\
\text { chá }\end{array}$ & Matingueiros & Wagner Miranda \\
\hline Angico & $\begin{array}{l}\text { Anadenanthera colubrina } \\
\text { ((Vell.) Brenan) }\end{array}$ & Matança & Xangai & Jatobá \\
\hline Araçá & $\begin{array}{l}\text { Psidium guineense } \\
\text { (SW.) }\end{array}$ & $\begin{array}{l}\text { Fulô do } \\
\text { Araçá }\end{array}$ & Dominguinhos & Dominguinhos \\
\hline \multirow[t]{2}{*}{ Aroeira } & $\begin{array}{l}\text { Myracrodruon urundeuva } \\
\text { (Allemão.) }\end{array}$ & $\begin{array}{l}\text { Pra fazer } \\
\text { chá }\end{array}$ & Matingueiros & Wagner Miranda \\
\hline & & $\begin{array}{l}\mathrm{ABC} \text { do } \\
\text { preguiçoso }\end{array}$ & Xangai & Xangai \\
\hline Açucena & Hippeastrum sp. & Sabor Colorido & Geraldo Azevedo & $\begin{array}{l}\text { Geraldo } \\
\text { Azevedo }\end{array}$ \\
\hline \multirow[t]{2}{*}{ Baraúna } & $\begin{array}{l}\text { Schinopsis brasiliensis } \\
\text { (Engler) }\end{array}$ & Sabor Colorido & Geraldo Azevedo & $\begin{array}{l}\text { Geraldo } \\
\text { Azevedo }\end{array}$ \\
\hline & & Matança & Xangai & Jatobá \\
\hline Cabriúva & $\begin{array}{l}\text { Myrocarpus frondosus } \\
\text { (Allemão LC) }\end{array}$ & Chá cutuba & Luiz Gonzaga & $\begin{array}{l}\text { Humberto } \\
\text { Teixeira }\end{array}$ \\
\hline Caju roxo & $\begin{array}{l}\text { Anacardium } \\
\text { occidentale } \\
(\mathrm{L})\end{array}$ & Pra fazer chá & Matingueiros & Wagner Miranda \\
\hline Canafístula & $\begin{array}{l}\text { Peltophorum dubium } \\
\text { ((Spreng.) Taub.) }\end{array}$ & Pra fazer chá & Matingueiros & Wagner Miranda \\
\hline
\end{tabular}

Revbea, São Paulo, V. 15, № 6: 154-172, 2020. 
Tabela 3: Flora da Caatinga: espécies de plantas que ocorrem na Caatinga presentes na letra de músicas regionais, seus cantores e compositores (Continuação).

\begin{tabular}{|c|c|c|c|c|}
\hline $\begin{array}{l}\text { Nome } \\
\text { popular }\end{array}$ & $\begin{array}{c}\text { Nome científico } \\
\text { (autor) }\end{array}$ & $\begin{array}{l}\text { Nome da } \\
\text { música }\end{array}$ & Cantores & Compositores \\
\hline Caroba & $\begin{array}{l}\text { Jacaranda } \\
\text { grandifoliata } \\
\text { (A.H.Gentry) }\end{array}$ & Chá cutuba & Luiz Gonzaga & $\begin{array}{l}\text { Humberto } \\
\text { Teixeira }\end{array}$ \\
\hline Carqueja & Baccharis sp. & $\begin{array}{l}\text { As plantinhas } \\
\text { do mato }\end{array}$ & $\begin{array}{l}\text { Renato Teixeira } \\
\text { Rolando Boldrin }\end{array}$ & $\begin{array}{l}\text { Renato Teixeira } \\
\text { Rolando Boldrin }\end{array}$ \\
\hline \multirow[t]{3}{*}{ Catingueira } & $\begin{array}{l}\text { Cenostigma } \\
\text { pyramidale } \\
\text { ((Tul.) Gagnon \& G.P. } \\
\text { Lewis) }\end{array}$ & Sabor Colorido & Geraldo Azevedo & $\begin{array}{l}\text { Geraldo } \\
\text { Azevedo }\end{array}$ \\
\hline & & $\begin{array}{l}\text { Catingueira } \\
\text { Fulorou }\end{array}$ & Dominguinhos & $\begin{array}{l}\text { Anastacia } \\
\text { Dominguinhos }\end{array}$ \\
\hline & & $\begin{array}{l}\text { Desafio do } \\
\text { Auto da } \\
\text { Catingueira } \\
\end{array}$ & Elomar & Elomar \\
\hline Catolé & $\begin{array}{l}\text { Syagrus cearensis } \\
\text { (Noblick) }\end{array}$ & Chá cutuba & Luiz Gonzaga & $\begin{array}{l}\text { Humberto } \\
\text { Teixeira }\end{array}$ \\
\hline Catuaba & $\begin{array}{l}\text { Erythroxylum } \\
\text { vacciniifolium } \\
\text { (Mart.) }\end{array}$ & Pra fazer chá & Matingueiros & Wagner Miranda \\
\hline Erva cidreira & $\begin{array}{l}\text { Lippia alba } \\
\text { ((Mill) N. E. Brown.) }\end{array}$ & Pra fazer chá & Matingueiros & Wagner Miranda \\
\hline Facheiro & $\begin{array}{l}\text { Pilosocereus } \\
\text { pachycladus } \\
\text { (Ritter.) }\end{array}$ & $\begin{array}{l}\text { Facheiros e } \\
\text { mandacarus }\end{array}$ & Alceu Valença & Alceu Valença \\
\hline Fedegoso & $\begin{array}{l}\text { Senna occidentalis } \\
\text { (L. Link) }\end{array}$ & Pra fazer chá & Matingueiros & Wagner Miranda \\
\hline Guariroba & $\begin{array}{l}\text { Syagrus oleracea } \\
\text { ((Mart.) Becc.) }\end{array}$ & Refazenda & Gilberto Gil & Gilberto Gil \\
\hline $\begin{array}{l}\text { Imburana } \\
\text { (de cambão) }\end{array}$ & $\begin{array}{l}\text { Commiphora } \\
\text { leptophloeos } \\
\text { ((Mart.) J.B.Gillett) }\end{array}$ & Matança & Xangai & Jatobá \\
\hline Jatobá & $\begin{array}{l}\text { Hymenaea } \\
\text { courbaril (L.) }\end{array}$ & Sabor Colorido & $\begin{array}{l}\text { Geraldo } \\
\text { Azevedo }\end{array}$ & $\begin{array}{l}\text { Geraldo } \\
\text { Azevedo }\end{array}$ \\
\hline \multirow{4}{*}{ Juazeiro } & & & & Luiz Gonzaga \\
\hline & $\begin{array}{l}\text { Ziziphus joazeiro } \\
\text { (Mart.) }\end{array}$ & Juazeiro & Luiz Gonzaga & $\begin{array}{l}\text { Humberto } \\
\text { Teixeira }\end{array}$ \\
\hline & & Matança & Xangai & Jatobá \\
\hline & & Pra fazer chá & Matingueiros & Wagner Miranda \\
\hline Jurubeba & $\begin{array}{l}\text { Solanum } \\
\text { paniculatum } \\
\text { (L.) }\end{array}$ & Pra fazer chá & Matingueiros & Wagner Miranda \\
\hline
\end{tabular}

Revbea, São Paulo, V. 15, № 6: 154-172, 2020. 
Tabela 3: Flora da Caatinga: espécies de plantas que ocorrem na Caatinga presentes na letra de músicas regionais, seus cantores e compositores (Continuação).

\begin{tabular}{|c|c|c|c|c|}
\hline $\begin{array}{l}\text { Nome } \\
\text { popular }\end{array}$ & $\begin{array}{l}\text { Nome científico } \\
\text { (autor) }\end{array}$ & Nome da música & Cantores & Compositores \\
\hline \multirow[t]{2}{*}{ Lírio } & \multirow[t]{2}{*}{ Habranthus sp. } & $\mathrm{Ei}$, flor & Xangai & Xangai \\
\hline & & Sabor Colorido & $\begin{array}{l}\text { Geraldo } \\
\text { Azevedo }\end{array}$ & $\begin{array}{l}\text { Geraldo } \\
\text { Azevedo }\end{array}$ \\
\hline \multirow{2}{*}{ Macambira } & \multirow{2}{*}{$\begin{array}{l}\text { Bromelia laciniosa } \\
\text { (Mart. ex Schult. \& } \\
\text { Schult.f.) }\end{array}$} & \multirow{2}{*}{$\begin{array}{l}\text { Catingueira } \\
\text { Fulorou }\end{array}$} & \multirow{2}{*}{ Dominguinhos } & Anastacia \\
\hline & & & & Dominguinhos \\
\hline \multirow[t]{4}{*}{ Mandacaru } & \multirow[t]{4}{*}{$\begin{array}{l}\text { Cereus jamacaru } \\
\text { (DC.) }\end{array}$} & Sabor Colorido & $\begin{array}{l}\text { Geraldo } \\
\text { Azevedo }\end{array}$ & $\begin{array}{l}\text { Geraldo } \\
\text { Azevedo }\end{array}$ \\
\hline & & $\begin{array}{l}\text { Paraíba mulher } \\
\text { macho }\end{array}$ & Luiz Gonzaga & $\begin{array}{l}\text { Luiz Gonzaga } \\
\text { Humberto } \\
\text { Teixeira }\end{array}$ \\
\hline & & Xote das Meninas & Luiz Gonzaga & $\begin{array}{l}\text { Luiz Gonzaga } \\
\text { Zé Dantas }\end{array}$ \\
\hline & & $\begin{array}{l}\text { Facheiros e } \\
\text { mandacarus }\end{array}$ & Alceu Valença & Alceu Valença \\
\hline Maracujá & $\begin{array}{l}\text { Passiflora } \\
\text { cincinnata } \\
\text { (Mast.) } \\
\end{array}$ & Pra fazer chá & Matingueiros & Wagner Miranda \\
\hline \multirow[t]{2}{*}{ Marmeleiro } & \multirow[t]{2}{*}{ Croton sp. } & Pra fazer chá & Matingueiros & Wagner Miranda \\
\hline & & Sabor Colorido & $\begin{array}{l}\text { Geraldo } \\
\text { Azevedo }\end{array}$ & $\begin{array}{l}\text { Geraldo } \\
\text { Azevedo }\end{array}$ \\
\hline Muçambê & $\begin{array}{l}\text { Tarenaya spinosa } \\
\text { ((Jacq.) Raf) }\end{array}$ & Roendo unha & Luiz Gonzaga & $\begin{array}{l}\text { Luiz Gonzaga } \\
\text { Luiz Ramalho }\end{array}$ \\
\hline $\begin{array}{l}\text { Não-me- } \\
\text { toque }\end{array}$ & $\begin{array}{l}\text { Mimosa pudica } \\
\text { (L.) }\end{array}$ & Frevo Mulher & Amelinha & Zé Ramalho \\
\hline Pau-ferro & $\begin{array}{l}\text { Libidibia ferrea } \\
\text { (Mart. ex Tul.) } \\
\text { L.P.Queiroz }\end{array}$ & Matança & Xangai & Jatobá \\
\hline Pau-pereira & $\begin{array}{l}\text { Aspidosperma } \\
\text { pyrifolium } \\
\text { (Mart.) }\end{array}$ & $\begin{array}{l}\text { Paraíba mulher } \\
\text { macho }\end{array}$ & Luiz Gonzaga & $\begin{array}{l}\text { Luiz Gonzaga } \\
\text { Humberto } \\
\text { Teixeira }\end{array}$ \\
\hline Pequi doce & $\begin{array}{l}\text { Caryocar brasiliense } \\
\text { (Cambess.) }\end{array}$ & Chá cutuba & Luiz Gonzaga & $\begin{array}{l}\text { Humberto } \\
\text { Teixeira }\end{array}$ \\
\hline $\begin{array}{l}\text { Quebra } \\
\text { pedra }\end{array}$ & Phyllanthus ninuri (L.) & Pra fazer chá & Matingueiros & $\begin{array}{l}\text { Wagner } \\
\text { Miranda }\end{array}$ \\
\hline Quixaba & $\begin{array}{l}\text { Sideroxylon } \\
\text { obtusifolium } \\
\text { ((Roem. \& Schult.) } \\
\text { T.D.Penn. ) }\end{array}$ & Pra fazer chá & Matingueiros & $\begin{array}{l}\text { Wagner } \\
\text { Miranda }\end{array}$ \\
\hline Taboa & $\begin{array}{l}\text { Typha domingensis } \\
\text { (Pers.) }\end{array}$ & Amanhã eu vou & Luiz Gonzaga & $\begin{array}{l}\text { Luiz Gonzaga } \\
\text { Beduino }\end{array}$ \\
\hline
\end{tabular}

Revbea, São Paulo, V. 15, № 6: 154-172, 2020. 
Tabela 3: Plantas que ocorrem na Caatinga presentes na letra de músicas regionais, seus cantores e compositores (Continuação).

\begin{tabular}{cllll}
\hline $\begin{array}{c}\text { Nome } \\
\text { popular }\end{array}$ & \multicolumn{1}{c}{$\begin{array}{c}\text { Nome científico } \\
\text { (autor) }\end{array}$} & Nome da música & Cantores & Compositores \\
\hline $\begin{array}{l}\text { Umburana } \\
\text { (de cheiro) }\end{array}$ & $\begin{array}{l}\text { Amburana cearensis } \\
\text { ((Allemão) A.C.Sm) }\end{array}$ & Pra fazer chá & Matingueiros & $\begin{array}{l}\text { Wagner } \\
\text { Miranda }\end{array}$ \\
\hline Xique-xique & $\begin{array}{l}\text { Pilosocereus gounellei } \\
\text { ( (F.A.C.Weber) Byles } \\
\text { \& Rowley })\end{array}$ & Sabor Colorido & $\begin{array}{l}\text { Geraldo } \\
\text { Azevedo }\end{array}$ & $\begin{array}{l}\text { Geraldo } \\
\text { Azevedo }\end{array}$ \\
\cline { 2 - 5 } & & $\begin{array}{l}\text { A Prosa Impúrpura } \\
\text { do Caicó }\end{array}$ & Elba Ramalho & Chico César \\
\hline
\end{tabular}

Fonte: Autoria própria.

A aplicação desse jogo musical em sala de aula pode ser feita incluindo atividades complementares, tais como a proposição aos alunos de pesquisas sobre informações adicionais sobre as espécies citadas nas músicas e incluídas no jogo. Poderia ser solicitado a eles que pesquisassem, por exemplo, o nome científico das espécies, o grupo taxonômico ao qual pertencem, os principais caracteres morfológicos das espécies ou do grupo de espécies do jogo, as relações ecológicas estabelecidas na Caatinga, os serviços ecossistêmicos prestados pelas espécies. Além das pesquisas podese propor que os alunos façam desenhos das espécies, destacando as características. Essas atividades podem ser utilizadas ao final do processo para uma exposição com desenhos (ou fotografias) e informações de destaque sobre a biodiversidade da Caatinga.

Em algumas músicas verificou-se na letra somente citação das espécies, essas músicas fornecem assim um registro da biodiversidade. Contudo, em outras músicas, além da menção ao nome da espécie, apresentam informações adicionais variadas sobre as espécies mencionadas, tais como aspectos morfológicos, ecológicos, comportamentais, etnobiológicos, dentre outros. Tais músicas podem servir de ponto de partida para pesquisas de verificação da veracidade das informações incluídas na letra.

A articulação com professores de outras disciplinas na atividade pode promover a interdisciplinaridade no ambiente escolar. A aplicação dessa atividade contribui de forma efetiva para abordagem da Educação Ambiental no ambiente escolar.

\section{Conclusões}

O estudo da fauna e da flora da Caatinga feito com realização de jogos que inclua músicas regionais pode favorecer 0 aprendizado sobre a biodiversidade desse ecossistema e demonstrar como as espécies de animais e plantas estão bastante relacionadas com a cultura musical. O jogo musical possibilita o entendimento do quanto é importante conhecer a biodiversidade e 
cuidar desse ecossistema que é tão rico e que requer ações de proteção. Esse jogo tem relevância especial para aplicação em escolas situadas na Caatinga, para que os estudantes tenham oportunidade de aprender mais sobre a fauna e flora nativas e para o engajamento dos mesmos em ações de conservação..

O uso de atividades lúdicas, como aplicação de um jogo musical, contribui é uma ferramenta que contribui para Educação Ambiental, para o ensino de Ciências Naturais e Biologia. O uso dessa atividade pode ser ampliado para abranger outras disciplinas e conteúdos, uma vez que esse tipo de atividade proporciona maior participação dos alunos no processo de aprendizagem.

\section{Agradecimentos}

Ao Programa de Pós-graduação em Ciência e Tecnologia Ambiental (PPGCTA) da Universidade de Pernambuco Campus Petrolina.

À Coordenação de Aperfeiçoamento de Pessoal de Nível Superior (CAPES), Brasil - Código de Financiamento 001.

À Fundação de Amparo a Ciência e Tecnologia do Estado de Pernambuco (FACEPE) pela concessão de bolsas e financiamento do projeto "Aprendendo sobre o valor da biodiversidade da Caatinga e seus serviços ecossistêmicos no ensino escolar" (FACEPE APQ - 0177-2.05/18).

\section{Referências}

ALMEIDA, E.F.; OLIVEIRA, E.C.; AQUINO, S.F. Proposta para o ensino de zoologia dos vertebrados a partir de paródias. Revista de Estudos e Pesquisas sobre Ensino Tecnológico (EDUCITEC), v. 3, n. 6, 2017.

ARAÚJO, G.M.; ABDO, J.P.; OLIVEIRA, A.K.M.; MATIAS, R. A música como instrumento de Educação Ambiental no contexto da pandemia. Revista Brasileira de Educação Ambiental (RevBEA), v. 15, n. 4, p. 205-219, 2020. https://doi.org/10.34024/revbea.2020.v15.10843

AZEVEDO, M.E.O.; OLIVEIRA, M.C.A.; LIMA D.C. A zoologia no ensino médio de escolas estaduais do município de Itapipoca, Ceará. Revista da SBEnBio, v. 3, n. 9, p. 6143-6154, 2016.

BACICH, L.; MORAN, J. Metodologias ativas para uma educação inovadora: uma abordagem teórico-prática (Série Desafios da Educação). Porto Alegre: Penso, 2018.

BARROS, M.D.M.; ZANELLA, P.G.; ARAÚJO-JORGE, T.C. A música pode ser uma estratégia para o ensino de ciências naturais? Analisando concepções de professores da educação básica. Revista Ensaio, v. 15, p. 81-94, 2013.

BRASIL. MINISTÉRIO DA EDUCAÇÃO. PCN Ensino Médio: orientações educacionais complementares aos Parâmetros Curriculares Nacionais Ciências. Brasília - DF: Ministério da Educação. 2008.

Revbea, São Paulo, V. 15, № 6: 154-172, 2020. 
BRASIL. Ministério do Meio Ambiente. Lista Nacional Oficial de Espécies da Fauna Ameaçadas de Extinção. Portaria MMA n. 444, de 17 de dezembro de 2014.

CAMARGO, F.; DAROS, T. A sala de aula inovadora: estratégias pedagógicas para fomentar o aprendizado ativo (Série Desafios da Educação). Porto Alegre: Penso, 2018.

CICILLINI, G.A. A evolução enquanto um componente metodológico para o ensino de biologia no $2^{\circ}$ grau. Educ. e Filos., v. 7, p. 17-37, 1993.

CONCEIÇÃO, A.R.; MOTA, M.D.A.; BARGUIL, P.M. Jogos didáticos no ensino e na aprendizagem de Ciências e Biologia: concepções e práticas docentes. Research, Society and Development, v. 9, n. 5, p. 1-25. 2020.

CRUZ, F.O.; OLIVEIRA, F.B. Revitalizando o processo ensino-aprendizagem em Administração. Cadernos EBAPE, v. 5, Ed. Especial, p. 1-13, 2007.

FERNANDES, M.F.; QUEIROZ, L.P. Vegetação e flora da Caatinga. Ciência e Cultura, v. 70, n. 4, p. 51-56. 2018.

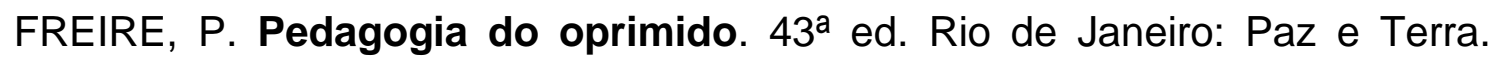
2011.

FREIRE, P. Pedagogia da autonomia. $53^{\underline{a}}$ ed. Rio de Janeiro: Paz e Terra. 2016.

GARDA, A.A.; LION, M.B.; LIMA, S.M.Q.; MESQUITA, D.O.; ARAÚJO, H.F.P.; NAPOLI, M.F. Os animais vertebrados do bioma Caatinga. Ciência e Cultura, v. 70, n. 4, p. 29-34, 2018.

KIOURANIS, N.M.M; SILVEIRA, M.P.; SILVA, E.L.; TANAKA, A.S.; ALVES, A.A.; THIAGO, C.A pertinência do estudo das propriedades ácido-base de compostos orgânicos no ensino médio. VII Congresso Enseñanza de las Ciencias. 2005.

KRASILCHIK, M. Prática de ensino de Biologia. São Paulo: EdUSP. 2004.

LEAL, I.R.; TABARELLI M.; SILVA J.M.C. Ecologia e conservação da Caatinga. Recife: Editora Universitária da Universidade Federal de Pernambuco, 2003.

LIMA, L. A. et al. "Musicalizando a Biologia": cantando e encantando através de paródias. Rev. Ciênc. Ext., v. 14, n. 2, p. 147-158, 2018.

MESSEDER NETO, H.S. O jogo é Excalibur para o ensino de Ciências? Apontamentos para pensar o lúdico no ensino de conceitos e na formação do professor. Actio: Docência em Ciências, v. 4, p. 77- 91. 2019.

MIRANDA, P.C.C. Jogo musical e humanização: um olhar lúdico, complexo e sistêmico na educação. São Paulo: Cultura Acadêmica. 2013.

MORO, M.F.; LUGHADHA, E.N.; FILER, D.L.;. ARAÚJO, F.S.; MARTINS, F.R. A catalogue of the vascular plants of the Caatinga Phytogeographical Domain: 
a synthesis of floristic and phytosociological surveys. Phytotaxa, v. 160, p. 1118, 2014.

PEIXOTO, A.G. O uso de metodologias ativas como ferramenta de potencialização da aprendizagem de diagramas de caso de uso. Periódico científico outras palavras, v. 12, n. 2, 2016.

QUEIROZ, L.P.; CARDOSO, D.; FERNANDES, M.; MORO, M. Diversity and evolution of flowering plants of the Caatinga domain". In: SILVA, J. C.; LEAL, I.; TABARELLI, M, (Eds.). Caatinga: the largest tropical dry forest region in South America. Cham: Springer, 2017, p. 23-63.

ROSÁRIO, C. S. Educação Ambiental e atividades lúdicas para a identificação da importância das distintas formas de vida (fauna e flora). Revista Brasileira de Educação Ambiental (RevBEA), v. 14, n. 3, p. 155-168, 2019.

RIBAS, L. C. C.; GUIMARÃES, L.B. Cantando o mundo vivo: aprendendo biologia no pop-rock brasileiro. Ciência \& Ensino, v. 12, p. 4-9, 2004.

SPIEL, C.; SCHWARTZMAN, S.A contribuição da educação para o progresso social. Ciência \& Trópico, v. 42, n. 1, p. 22-86. 2018.

VIEIRA, A.S. Uma alternativa didática às aulas tradicionais: o engajamento interativo obtido por meio do uso do método peer instruction (instrução pelos colegas). Dissertação de mestrado, Universidade Federal do Rio Grande do Sul, Porto Alegre, RS, Brasil. 2014. 